\title{
Dementia and elder abuse: Understanding public health nurses' experiences
}

\author{
P.J. Cooke*1, Mary Rose Day ${ }^{2}$, Helen Mulcahy ${ }^{2}$ \\ ${ }^{1}$ St. Finbarr's Hospital, Douglas Road, Cork, Ireland \\ ${ }^{2}$ School of Nursing and Midwifery, Brookfield Health Sciences Complex, University College Cork, Cork, Ireland
}

Received: December 20, 2018

Accepted: March 11, 2019

Online Published: March 26, 2019

DOI: $10.5430 /$ jnep.v9n7p56

URL: https://doi.org/10.5430/jnep.v9n7p56

\begin{abstract}
Elder abuse (EA) within the population of community dwelling older people living with dementia is significantly more prevalent when compared with the population of older adults without cognitive impairment. Public Health Nurses (PHNs) in Ireland are a key professional service provider group in safeguarding vulnerable populations. Interpretative Phenomenological Analysis (IPA) was utilized to explore the experiences of PHNs in identifying and addressing abuse, among community dwelling older adults living with dementia that was perpetrated by informal caregivers. Semi-structured interviews were conducted with PHNs $(\mathrm{n}=$ 5) in Ireland that had in the previous 12 months dealt with a case of elder abuse involving an older adult living with dementia. Analysis of the data revealed three super-ordinate themes; identifying hidden abusive relationships; Complexity - 'where do I start'; and Isolation. This study provides unique insights from PHNs relevant to safeguarding this particularly vulnerable group. Specific implications for practice and recommendations are presented.
\end{abstract}

Key Words: Elder abuse, Dementia, Public health nurse, Older adult, Safeguarding

\section{INTRODUCTION}

Dementia and elder mistreatment are recognized internationally as prevalent and growing public health issues. Dementia is a progressive condition where structural and chemical changes arise within the brain as a result of neurodegenerative changes. ${ }^{[1]}$ Worldwide the number of people living with dementia in 2015 were almost 47 million and by 2050 projections are that 135 million people will have some form of dementia. ${ }^{[2,3]}$ Government policy in Ireland ${ }^{[4]}$ and internationally ${ }^{[5,6]}$ view dementia as a public health priority and endorse the need for a strategic response. Dementia has a huge economic cost for society, family and individuals globally, and has major implications for health policy and practice. Dementia is a substantial risk factor for all forms of abuse especially as dementia progresses. ${ }^{[7-9]}$
The legislative and policy context to safeguarding adults, mental capacity legislation and service approaches differ internationally to prevent and manage incidents of elder abuse. $^{[10-12]}$ In Ireland, current Safeguarding Vulnerable Adults policy ${ }^{[10]}$ for protection of adults at risk of abuse needs strengthening and expansion. ${ }^{[13]}$ In recognition of this, a National Safeguarding Office (NSO) was established in 2015. In addition, the Health Information \& Quality Authority and the Mental Health Commission are working on the development of national standards for adult safeguarding, the Adult Safeguarding Bill (2017) is under review, and the implementation of the Assisted Decision-Making ${ }^{[14]}$ Capacity Act 2015 is in progress. ${ }^{[15]}$

Prevalence and estimates of elder abuse can vary widely

*Correspondence: P.J. Cooke; Email: pj.cooke@ hse.ie; Address: St. Finbarr’s Hospital, Douglas Road, Cork, Ireland. 
across countries, states, cultures, and socio-political jurisdictions. Dong (2015) ${ }^{[16]}$ conducted a systematic review to analyze global epidemiology of elder abuse in terms of its prevalence, risk factors, and consequences. Prevalence of elder abuse was $47.3 \%$ in older adults with dementia in North and South America compared to $10 \%$ in cognitively intact older adults. In Ireland, 33\% of clients reporting abuse had dementia. ${ }^{[17]}$

The causal mechanisms between elder abuse and dementia are complex and multifaceted. Numerous factors within the perpetrator/victim dyad have been identified as increasing the risk of abusive behaviors occurring. Depression, cognitive impairment, ${ }^{[18-20]}$ functional decline, ${ }^{[21]}$ social isolation, history of domestic violence, alcohol and substance abuse, agitation and aggression can increase the likely hood of abuse occurring. ${ }^{[20,22-24]}$ Caregiver burden, stress, psychological and mental health of the perpetrator is a risk factor for elder abuse especially among carers of adults living with dementia. ${ }^{[24]}$

Health professionals, especially community nurses, doctors, and social workers play an important role in detecting, reporting, and safeguarding adults at risk of abuse ${ }^{[25-31]}$ and caring for people with dementia. ${ }^{[32]}$ However professionals often have difficulty in recognizing suspected cases of elder abuse ${ }^{[33]}$ and report barriers to managing and reporting of abuse. This is a consequence of lack of confidence and knowledge regarding defining and diagnosing abuse ${ }^{[19]}$ and role uncertainty. ${ }^{[34,35]}$ Lack of role clarity has been identified among health professionals and health center staff, ${ }^{[35,36]}$ volunteers $^{[35]}$ general practitioners ${ }^{[37,38]}$ and paramedics. ${ }^{[39]}$ Role uncertainty can result in tolerance of abusive behaviors $^{[40]}$ and can be a contributing factor in interdisciplinary friction and apathy with reporting mechanisms. ${ }^{[34]}$ General Practitioners ${ }^{[28]}$ reported feeling underprepared for management of elder abuse perpetrated by family carers. GPs were frustrated that some nurses distanced themselves once they passed on suspected concerns. ${ }^{[28]}$ In addition, inappropriate referrals to social workers can result in interdisciplinary friction. ${ }^{[41]}$ Clinical experience and an individualized approach to assessment, as well as a wide range of support is necessary to handle effectively suspected elder abuse cases. However, this was not evident in the study. ${ }^{[42]}$

Schmeidel et al. (2012) $)^{[43]}$ examined the perspectives of healthcare professionals on detection and reporting of elder abuse. Nurses and physicians were not as knowledgeable of elder abuse matters compared with social workers, and nurses were unsure of their role. Phelan $(2010)^{[44]}$ reported that Irish community nurses viewed elder abuse as being beyond their professional scope. In addition, a Chinese study of 245 student nurses perceptions of elder abuse found that $57.2 \%$ of first year students and $38.5 \%$ of third year students viewed detection of elder abuse as the responsibility of social workers. ${ }^{[45]}$

A study by Erlingson et al. (2012) ${ }^{[46]}$ used a questionnaire based on three hypothetical cases of elder abuse to examine Swedish community-based nurses $(\mathrm{n}=81)$ and Japanese Public Health Nurses $(n=124)$ experience and responses to abuse. Swedish nurses described an approach that was practical, action-oriented and involved high levels of suspicion and personal intervention to attain increased control over situations. Japanese PHN responses showed more understanding of family member's situation, and collaboration was a key aspect of interventions. Both Swedish and Japanese nurses despite cultural differences showed a global 'humanness' to the issue of elder abuse.

Sandmoe et al. (2011) ${ }^{[42]}$ reported that intuition and experience were key factors in identification of suspected elder abuse cases. Clinical assessment was informed by ability of the nurse to observe home situation of client; quality of the information gathered about clients; support of manager and alliances. Assessment is a process and determination of elder abuse cannot be based on a single encounter. ${ }^{[47]}$

A literature review by Cooke et al. (2017) ${ }^{[27]}$ sought to analyze professionals' perceptions and experiences pertaining to the identification, assessment and handling of elder abuse. They concluded that community professionals have a key role in the identification, assessment and handling of elder abuse cases, but approaches within community settings are often fragmented. Furthermore, intuition and experience as sole endeavors are not best practice. Both nurses and social workers perceive that lack of support, and working in isolation is a recurrent finding within the literature. ${ }^{[35,42,48-50]}$ Working in isolation with complex cases can mitigate against shared decision-making. ${ }^{[42]}$

Cairns and Vreugdenhil (2014) ${ }^{[48]}$ reported that frontline professionals struggle with ethical issues. Balancing right to self-determination with safeguarding obligations and attitude of professionals can influence how they respond to elder abuse. Doron and Marnin (2013) ${ }^{[51]}$ reported that nurses were significantly more agreeable to provide information to victims of elder abuse than their willingness to report elder abuse. DeLiema et al. (2015) $)^{[34]}$ reported that improved communications between healthcare professionals and adult protection social workers can optimize outcomes for victims of elder mistreatment.

Health and social care professionals face additional challenges when dealing with cases of elder abuse involving 
older persons living with cognitive impairment. ${ }^{[42,48,49]}$ No studies were found that specifically researched professional perspectives involving elder abuse of older people living with dementia. The perceptions and experiences of nurses working with cases of elder abuse are important and can inform future practice. Thus, this study explored the experiences of PHNs in identifying and addressing abuse among community dwelling older adults living with dementia perpetrated by informal caregivers.

\section{Methods}

An Interpretative Phenomenological Analysis (IPA) design was used in this study. IPA is an approach to qualitative research, described by Smith et al. (2009) ${ }^{[52]}$ as being underpinned by the paradigms of phenomenology, hermeneutics and idiography. Furthermore, the focus is on understanding people as being immersed in a world of people, objects and relationships. ${ }^{[52]}$ Hence, the IPA researcher seeks to generate understanding of an individual's experience of his/her involvement within the lived world. IPA is concerned with the detail that an experience means for an individual and interpreting what sense the person generates about what has happened to them. Larkin and Thompson (2012) suggest that successful IPA research will include the elements of "giving voice" to the research participants and will enable "making sense" of the participant's experiences through interpretation. ${ }^{[53]}$

\subsection{Setting}

The setting chosen for the study was the workplace of public health nurses i.e. Primary Care Centers in a two Local Health Office (LHO) areas. Although participants could have been interviewed away from the workplace all elected to be interviewed in their own primary care centers.

\subsection{Sample}

The IPA design of this study required the utilization of a purposive approach to sampling. Smith et al. (2009) highlight that an IPA approach entails recruiting participants based on the unique insight they can provide on the phenomenon being investigated. ${ }^{[52]}$ The selection criteria utilized to select participants for this study included:

(1) Participants were public health nurses.

(2) Participants must have been involved with a case of elder abuse within the previous 12 months involving older adults with cognitive impairment.

(3) The older adult must have been residing in the community setting such as their own home or the home of a family/informal carer.

(4) The perpetrator of the abuse must have been an informal caregiver. This included anyone providing care/support in a non-professional capacity such as family members, friends, neighbors and acquaintances.

IPA seeks to reveal a rich detailed account of an individual's experience. Therefore a sample is required that will provide sufficient quality data that allows insightful analysis to be developed. For the purposes of this study, the researcher recruited a sample of five participants sufficient to enable analysis of significant similarity and differences between the participants.

\subsection{Recruitment}

The study had ethical approval from the Clinical Research Ethics Committee of the Cork Teaching Hospitals and permission to access participants from two Directors of Public Nursing in the south of Ireland. These latter were asked to identify potential PHNs in their jurisdiction meeting the inclusion criteria for the study. Once identified the researcher (PJC) sent a letter of invitation to the PHN with a Participant Information Leaflet and consent form. Arrangements were then made for interview.

\subsection{Interview protocol}

Semi-structured interviewing gives flexibility to the researcher to explore novel areas in the pursuit of richer data. An interview schedule was formulated as a means of facilitating and guiding the interview, but remaining mindful of the importance of allowing respondents to determine how the interview proceeded. Smith and Osborn (2004) advise that adopting this approach may lead to unpredicted, but extremely pertinent data. ${ }^{[54]}$ The phenomenon being explored in this study had the potential to be emotive for both study participants and researcher. A study to explore the difficulties that nurse researchers encounter when conducting semi-structured interviews concluded that nurses must clearly define distinction between the roles of nurse and researcher. ${ }^{[55]}$ Failure to do so may result in the investigator becoming too emotively involved, resulting in bias. All of these factors were considered in a reflexive way by the primary researcher (PJC) throughout the research process.

Interviews were recorded using a Sony ICD-UX533 digital recorder and field notes were taken during and after interviews to capture observations at the time. Alternative names were assigned to PHN participants and clients in their caseload to protect their identities and a transcribing convention was compiled.

\subsection{Data analysis}

Data were analyzed manually in line with the requirements of IPA. 


\section{Findings}

All participants were female and were employed as PHNs for between 2 and 15 years. They managed both urban (Carol, Kate and Paula) and rural (Sarah and Emer) areas, and were involved in cases of physical, psychological and financial abuse as well as neglect. All the clients at the center of these experiences were over 65 years and had a diagnosis of dementia. One woman (Ms C), who was living alone and one man $(\mathrm{Mr} \mathrm{D})$ in sheltered housing were both befriended by younger men for financial gain. An older cohabiting sibling and a visiting niece cared for one elderly woman (Ms E). Three (Mr. and Mrs A and Mrs B) were living with family, the latter with a separated adult son and the former husband and wife with adult sons or daughters.

The focus of the findings presented here are an exploration of the experiences of the PHNs but will naturally relate to the context of the community dwelling older adults. A schematic presentation of the three super-ordinate themes and their component sub-ordinate themes is presented in Figure 1.

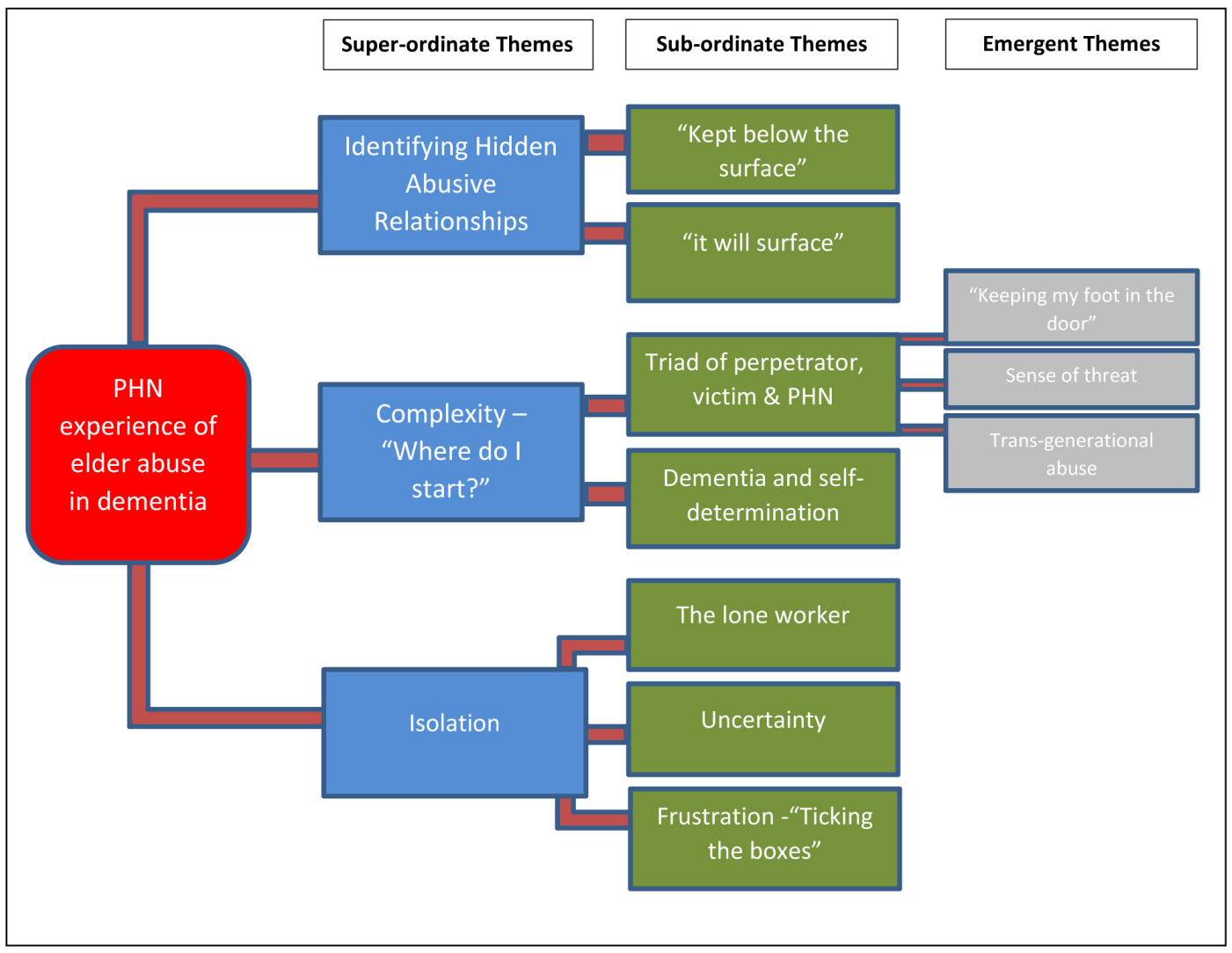

Figure 1. Diagram of super-ordinate themes and their component sub-ordinate themes

\subsection{Identifying hidden abusive relationships}

Identifying hidden abusive relationships emerged from the sub-ordinate themes kept below the surface and it will surface. These themes encompass the challenges PHNs' experienced while working with older adults living with dementia that were being covertly abused by an informal carer and the experience of the PHN in discovering that abuse was occurring.

The concealed aspect of elder abuse was present in the experiences of all the participants. Paula recounts her experience of dealing with Mrs A, a woman who had early onset dementia that was being abused secretly by her son:

These problems were very much kept below the surface and we weren't really in contact with her, except for the occasional wound dressing for leg ulcers. (Sarah, line 31-34)

Sarah's use of the phrase "kept below the surface" generates an image of something that has been buried. This resonates with Paula's description of the elder abuse in a case she dealt with as being "very well disguised". (Paula 223)

Participants' experienced varying reasons for the concealment of abusive relationships. The description of a vulnerable older woman attempting to conceal her financial abuse from public gaze can be attributed to a sense of shame:

She started giving us more information about 
how much money she had given and when we had a final meeting with her she actually admitted she may have gave him too much money and she didn't know what she was doing at that time, so I think when she reflected back on it, she knew she had been caught and she said herself she was embarrassed. (Kate, line 180-186)

PHNs also experienced the controlling relationship between the abuser and the abused as a factor in the concealment of the abusive relationships. Paula's experience with a niece that was visiting her two older aunts and "had the main control over this older lady (Mrs E) with dementia" (Paula, 19), which resulted in the aunts being "afraid of the niece" (Paula, 80) and unwilling to report financial abuse.

This is also present in Sarah's experience of a "BULLYING" son "who was ruling the roost completely and it was his word... his way or no way”. (Sarah, line 80-81)

The concealment of abuse in the relationship between abuser and abused was also a factor where the victim did not recognize that abuse is occurring and even perceived the relationship with the abuser as a beneficial one. Kate describes her experience of working with Mrs C, a woman with dementia that had been financially exploited:

She was quiet fond of this man that was calling to her and she befriended him as she was lonely and isolated. (Kate, 60-61)

Paula presents a potential cultural component to the concealment of abuse in Ireland:

The old fashioned thinking is, especially in Ireland... it wouldn't have been because I did nursing care of the older adult in Australia, but in Ireland its always protect the family name... it's something that's been... I suppose every. . . every country have their own issues, so a lot goes back to the poverty that older people experienced here, it's all, to me it's all intertwined, all intermixed. ALWAYS PROTECT THE FAMILY NAME. If you look at the history of Irish, everything, because of the Catholic Church, everything was swept under the carpet. It's not just with, because we, we know what happened with the Catholic Church, but it would also be, that's Catholic Ireland in the twenties thirties and forties, 'protect the family name'. (Paula, line 273-282)

Paula intimates that the concealment of abuse in Ireland can be linked with the country's strong Catholic heritage and a misguided cultural sense of morality.

PHNs described having an intuitive sense of something strange within the relationship between the older person and the suspected abuser. This was expressed simply as "a feeling" [Emer, line 319] in relation to a man that was visiting a vulnerable older woman (Ms G):

I was just suspicious and you know... it just didn't match, or you know it didn't, I thought it was unusual and strange, that here's a chap we never knew before, just came on the scene. (Emer, line 329-332)

PHNs utilize such intuitive feelings as a motive to dig deeper:

She has got home help so she is a regular client of mine and she is a vulnerable adult, that I would have been involved in her care anyway. It was just one day the conversation led into... she was in bad form and I probed as to why she was in bad form. (Carol, line 27-30)

Paula highlights the role of carer burden in cases of elder abuse and acknowledges that "carers have to get frustrated" caring for an older person with dementia. Building a relationship with carers as well as clients facilitates the disclosure of abusive behavior:

It will jump at you, if you call, you know at various times that you can call unannounced or say I'll be there this afternoon and to sit there if you have the time to sit back and relax, spend the time, talking, communicating with the dementia patient, and also have that time with the carers and the family members... and one family member might not be happy with the other family member. If you have the time, if you can take the time with these families, it will come out, it will surface. (Paula, line 314-320)

\subsection{Complexity - "where do I start?"}

This super-ordinate theme refers to the complexity encountered by PHNs in dealing with cases of elder abuse in the presence of cognitive impairment. The first sub-ordinate theme is Triad of perpetrator, victim and PHN and refers to PHNs' complex navigation of power relationships within cases of elder abuse among older adults with dementia. The second subordinate theme of Dementia and self-determination refers to the difficulty faced by PHNs in balancing respect for a person's right to self-determination, while also being mindful of the need to safeguard the welfare of the vulnerable adult. 
Identifying and negotiating around the power relationships between the victim and the perpetrator was a factor for all the participants. In the case involving Bill's abusive relationship towards his parents (Mr \& Mrs A), Sarah recounts the difficulty she had comprehending the dynamics within this chronic abusive scenario:

It was very difficult; it was very difficult to put it into a box because it was such a complex family situation that had gone on for so long. (Sarah, line 84-86)

The complexity of this relationship within the triad of victim, perpetrator and PHN culminates in the PHN having to compromise her own value system:

The eldest Son... I did my best to get along with him because I thought, there is no point, creating a situation where I wouldn't be welcomed and it was a very difficult balance between saying no, this can't be happening, you can't do this, and, keeping my foot in the door. (Sarah, line 135-140)

The necessity to compromise one's personal values in order to maintain a relationship with the perpetrator of abusive behavior is also referred to in Paula's experience:

I find the one thing that would be most upsetting for me....as, a visiting health professional is when you are visiting somebody's home. If you find...the verbal abuse to a dementia patient, it is very hard to sit back and you have to, sit back and you can't say anything because you are a guest in somebody's home. (You) must be mindful that you are actually a guest, they can ask you to leave. (Paula, line 335-339)

A sense of threat in dealing with cases of elder abuse among older people with dementia was a subordinate theme that emerged from the experiences of three participants.

Sarah recounted her experience of being threatened by a perpetrator suspected of abusing his mother with dementia:

He got so irate that he phoned me up about half past six one night and told me that he was going to 'fuck me over' and that he was going to seek my boss and 'fuck her over' as well. These were the words he used, he was very aggressive, very abusive. (Sarah, line 281-285)

Such threatening behavior is also described by Paula in her encounter with Mary, a niece that was financially and psychologically abusing her aunts:

Published by Sciedu Press
The niece would literally... become abusive to me, 'I had no right, to put her aunt into respite care'. Very abusive. (Paula, line 46-47)

Such incidents were psychologically traumatic for participants and left them feeling:

Frightened at the time because it was very personal and, it was very frightening. (Sarah, line 288)

You would feel threatened. (Paula, line 49)

While not directly threatened by the perpetrator of abuse, Carol does outline her awareness of the potential risk:

I don't feel threatened by this guy. .. but you are still challenging somebody on the care they are giving to their Mother or Father or whatever, the Mother in this case, you know. I would, I would have met him here in the Health Center rather than going to the house, and I suppose that was more for my own protection as well. (Carol, line 308-312)

\subsection{Isolation}

This super-ordinate theme relates to the overall sense of working in isolation experienced by PHN's when working with complex cases of abuse involving older people with dementia. This super-ordinate theme emerged from three subordinate themes, The lone worker; Uncertainty and "Ticking the boxes" - a sense of frustration.

The sub-ordinate theme 'The lone worker' reflects the sense PHNs express of being on their own with these complex cases:

I found it difficult that the case was closed by the Social Worker. You know we can't close cases... The fact that other professionals can open cases and close cases, it's still...I suppose a lot of responsibility to land on my shoulders or the Public Health Nurses shoulders that if things escalated, and I know that I can always re-refer, but the fact that there is nobody else working actively on the case, it's quite difficult. (Carol, line 315-319)

Carol's use of the phrase "my shoulders" creates a picture of a person carrying a weight of responsibility on her back. This sense of carrying a weight on her own is also exemplified by Sarah's description of how she feels in relation to her case involving $\mathrm{Mr}$ and $\mathrm{Mrs} \mathrm{A}$ : 
There's nothing to help you change it. And when you're having to go in twice a week and watch the same situation and know there's nothing you can do about it, it's emotionally draining... You just think, you know, what we are doing here. (Sarah, line 479-483)

This sense of working in isolation is highlighted in Paula' description of not being able to "bounce something off another person."

We don't have the mechanisms in place that when I see a case of elder abuse, I cannot come back to my Health Center and pick up the phone to somebody, run it by them and say, look I think this is going on, can I have a second opinion, could you make a visit with me or am I reading too much into it? NO MATTER HOW LONG you're ever in the job, you'll always need to bounce something, because we're lone workers and we need to bounce something off another person. (Paula, line 294-300)

The sub-ordinate theme Uncertainty incorporates the dilemma PHNs face when deciding what course of action to take in relation to cases of elder abuse. Kate and Carol expressed uncertainty regarding what course to action should be taken in relation to suspected elder abuse:

As Public Health Nurses we deal with kids as well, there is, you are very quick to refer a child to Social Work Services. When you know something is not right and even if we weren't one hundred percent sure we would always send a referral anyway for investigation. Whereas I feel sometimes with adults do we just sit back a small bit and see where it goes. (Kate, line 617-621)

The same uncertainty of role is present in Carol's recounting of whether or not to make a referral to the Safeguarding and Protection Team:

I suppose in this case, specifically I didn't know whether I should or shouldn't, you know it took a while before I actually sent the referral so I thought about it... but didn't have any specific grounds for it so I actually addressed it with the family, or with the Son. But things didn't change, so then I felt it was appropriate to refer on then. (Carol, line 228-231)
Carol outlines how she attempted to resolve the abusive situation between Mrs B and her son before seeking support. Uncertainty is also a feature of Sarah's experience in deciphering whether a certain behavior constitutes abuse or neglect and she attributes this professional dilemma to the lack of Social Work resources:

Getting access to Social Workers... They're swamped. It's very hard to get them down, it's very hard to sort of... It's got to be one heck of a case before they even take it on, and in the meantime you're struggling, thinking what am I even going to do with this one, is it abuse, is it neglect? It's got to be quite specific before they even look at it. (Sarah, line 388-394)

A sense of frustrating uncertainty that is echoed by Kate:

Going back to the problem of Safeguarding, like the referrals we are sending in are not meeting the criteria. There being knocked back to us again, saying it does not fit the criteria for Safeguarding. So now we're in limbo with certain clients again, they don't deem the case high enough priority to be investigated. So I feel we're back around this now again, that we're now prioritizing the cases and others are being left back to us again until they get to extreme level where there is abuse and it wasn't prevented. (Kate, line 552-560)

Some PHNs felt frustration regarding the processes surrounding Safeguarding and Protection and intimated that not enough is achieved through this infrastructure:

It has gone on for years. It's just the bottom line of it, you feel...You feel so powerless against them (perpetrators) in all of this. I get really pissed off, meeting after meeting, case conference after case conference, safeguarding and protection. All we are doing is ticking the boxes and covering our arses, that's all it is. We've had three Safeguarding \& Protection Conferences about this case. (Sarah, line 532-538)

This frustration is also present in Kate's description of referring suspected cases of elder abuse to the Safeguarding and Protection Team:

But then it's like that if my referral isn't taken serious and if it's knocked back, then I feel why raise it and wasting my time filling out this paperwork if nothing is being done about it. (Kate, line 624-627) 
The frustration expressed in these extracts is suggestive of health professionals that are showing signs of apathy and as seen here in Sarah's next extract, an emerging sense of resignation:

But I'm at the point of realizing that there are some things... it's like the prayer to St. Francis, 'I can be encouraged to change the things I can... serenity to accept the things I cannot change and wisdom to know the difference. (Sarah, line 302-307)

Positive experiences were described by two of the participants in relation to Safeguarding and Protection meetings:

I found that Safeguarding meetings good... Everybody in the primary care knows that the other person is doing, or that they don't think they'll do that or somebody else will do this, I think if everybody is clear about what everybody else is doing. The facts are put before everybody (Emer, line 541-545).

However when asked if training or instruction had been received in relation to the new elder abuse reporting policy "Safeguarding Vulnerable Persons at Risk of Abuse: National Policy \& Procedures" which was launched by Minister Kathleen Lynch on 5th December 2014, all the participants replied "No".

\section{Discussion}

This study has explored and interpreted five PHNs experiences in identifying and addressing abuse among community dwelling older adults living with dementia perpetrated by informal caregivers.

Approximately 18,000 older adults experience one or more forms of elder abuse annually based on prevalence estimates and population aged over 65 years. ${ }^{[44,56]}$ The Health Service Executive ${ }^{[57]}$ received 9,500 safeguarding concerns and included adults under and over 65 years. Safeguarding concerns present only a tip of the iceberg and a large amount of abuse is undetected.

An estimated 56,000 people are living with dementia in Ireland ${ }^{[58]}$ worldwide 47 million have dementia and by 2031 this is expected to increase to 131.5 million. ${ }^{[59]} \mathrm{A}$ decline in cognitive function significantly increases risk for all forms of elder abuse. ${ }^{[60,61]}$ Signs of abuse can be misinterpreted as part of normal disease progression. ${ }^{[8]}$ Older adults living with dementia experience significantly higher rates of elder abuse when compared with the population of older adults without dementia. ${ }^{[62,63]}$ Abuse of older adults with dementia

Published by Sciedu Press is under-reported because detection is often compounded by multiple risks related to individual, relational, cultural and social factors.

Participants is this study described the cyclical kind of concealment and the hidden nature of abuse. A definition of undue influence by California Probate Code ${ }^{[64]}$ identifies four components: victim vulnerability, alleged influencer authority, tactics, and outcomes. The factors that facilitated concealment of abuse included: embarrassment, secrecy, individuals not recognizing they were being abused, fear and undue influence, the Irish catholic heritage, and culture of protecting the family name. This is supported in the literature particularly in relation to concealment, fear of reprisal and lack of awareness that abuse is occurring. ${ }^{[65]}$ Building a relationship with older adults and informal carers was a key factor in the PHN 'keeping her foot in the door' in this study.

Participants described intuitive processes and suspicions that something was 'not quite right', and probed to draw out the facts to uncover abusive behaviors. Benner (1984) found that experienced expert nurses displayed a level of judgment and understanding of clinical situations not found in novices. ${ }^{[66]}$ Similarly, intuition, suspicions and experience were factors used by public health nurses, nurses, auxiliary nurses, social workers and care workers in the identification of suspected elder abuse cases. ${ }^{[42,46]}$ Recognizing suspected cases of elder abuse can be difficult. ${ }^{[33]}$ The first step in clinical assessment is recognition of a possible abuse situation, followed by the gathering of evidence from a wide range of sources, observation, judgement, decision making and conclusion. ${ }^{[42]}$

The literature supports a complex link between elder abuse and vulnerability of the person who is being abused, which is predominantly associated with cognitive impairment, mental illness, caregiver's stress, history of domestic violence, alcohol and substance abuse and past financial exploitation. ${ }^{[22]}$ Perpetrator characteristics associated with greater risk of abuse among older adults living with dementia is psychological and mental health and caregiver burden. ${ }^{[22,47]}$ Dementia imposes physical, psychological, and financial stress on patients, caregivers and family members. Caregiver burden has been associated with a higher risk of mistreatment. ${ }^{[68]} \mathrm{A}$ Cochrane review reported some evidence that empowering and teaching coping skills to family carers of persons with dementia might improve situations of abuse. ${ }^{[69]}$ Australian and Norwegian nurses' actions and responses to abuse were allied to the gravity of the case and the cognitive ability of the victim. ${ }^{[42]}$

The complexity of situations that participants in this study were involved in were multifaceted. The results of this study are in agreement with other studies in this field. The litera- 
ture indicates that complex practical and ethical challenges can arise in the management of elder abuse that transcends relationships issues, perpetrator/victim dyad, practitioners and service provider. ${ }^{[49]}$ Similarly, social workers found balancing autonomy and self-determination of adults with issues of capacity, risk and vulnerability requires good decisionmaking and sound ethical judgements. ${ }^{[70]}$ The causal mechanisms between elder abuse and dementia are intricate adding to complexity. ${ }^{[71]}$

Participants in this study had no training update on Safeguarding Vulnerable Adult Policy ${ }^{[10]}$ and described uncertainty isolation and frustration in processes surrounding safeguarding and protection. The literature points to isolation as a key factor ${ }^{[35,42,48,50,70]}$ and this can diminish shared decision-making. ${ }^{[42]}$ General practitioners similarly felt isolated from nurses and social workers when managing elder abuse cases. ${ }^{[28]}$ Training and continuing education can influence knowledge and attitude of professionals and promote the detection and reporting of elder abuse. ${ }^{[19,72]}$

Ireland lacks a legislative framework for responding to safeguarding concerns and managing interventions. ${ }^{[15]}$ Donnelly and O'Brien (2018) stated "current mechanisms for responding to the prevention and the protection of adults at risk of abuse in Ireland can be described as ad hoc and reactionary" (p.3) and these can lead to inadequate reporting. ${ }^{[73]}$

The present findings should be interpreted with caution owing to a number of limitations. The use of a small purposeful sample from two LHO areas may have yielded a particularly motivated sample whose experiences may have differed from PHNs generally. There is the possibility that some of the nurses may have been reluctant to share all aspects of their experiences. However, the use of IPA as a methodology did produce clear, rich and insightful findings, which can inspire future studies.

\section{Conclusion}

In summary, our findings provide a unique insight into PHNs experiences of identifying and addressing abuse among community dwelling older adults living with dementia. The issue of elder abuse will continue to be a serious and complex public health concern that is largely hidden and underreported. Adults with dementia can be viewed as unreliable witnesses and nurses have difficulty in identifying abusive relationships and recognizing suspected cases of elder abuse. Multiple risk factors encountered by nurses related to individual, relational, cultural and social issues. Complex ethical challenges, lack of role clarity, experience, uncertainty and isolation can be frustrating and influence decision-making and safeguarding responses. Unclear safeguarding policies and absence of elder abuse legislation can result in inadequate reporting. Training on detection and reporting of elder abuse and legal literacy can influence the knowledge and attitudes of professionals' decision-making.

\subsection{Implications for nursing practice}

PHNs are the main source of referrals of suspected elder abuse cases into the safeguarding and protection teams after the voluntary sector. There has been a significant increase in safeguarding referrals thus it is vital that their practice is evidence based. Identification of elder abuse among people with dementia is particularly challenging. Although PHN intuition plays a significant role, it needs to be supported by specific training, skills development and supervision. Building and maintaining a therapeutic relationship with the older person and their carer is fundamental to uncovering the abuse and facilitating continuing interventions. The consequent demands of this delicate role require PHNs to consider supportive mechanisms for self-preservation.

\subsection{Recommendations}

Develop evidence-based methods of improving training and continuing professional development for PHNs in relation to detecting and reporting of elder abuse in persons with dementia.

National standards, policies, procedures and guidelines including referral pathways should be developed to support all Health and Social Care professionals in recognizing and responding to elder abuse in persons with dementia.

PHNs should have access to clinical supervision and support when managing complex cases to minimize the effects of isolation and distress.

PHNs should be supported to maintain a therapeutic relationship with clients and their carers to ensure that health care remains available and accessible.

A formalized case management approach to care should be considered in such complex cases supported by the development of an integrated care model at health service level.

Research be conducted to investigate the role of transgenerational transmission of violence plays in elder abuse.

Research on how cognitive impairment affects elder mistreatment investigation.

\section{CONFLiCTS OF INTEREST Disclosure}

The authors declare that there is no conflict of interest. 


\section{REFERENCES}

[1] Qiu C, von Strauss E, Backman L, et al. Twenty-year changes in dementia occurrence suggest decreasing incidence in central Stockholm, Sweden. Neurology. 2013; 80(20): 1888-94. PMid:23596063 https://doi.org/10.1212/WNL.0b013e318292a2f9

[2] Alzheimer's Disease International. Dementia Statistics. London: ADI; 2013.

[3] Bail A, Morini G, Newman RS. Look at the gato! Code-switching in speech to toddlers. Journal of Child Language. 2015; 42(5): 1073101. PMid:25362846 https://doi .org/10.1017/S030500091 4000695

[4] Department of Health. The Irish National Dementia Strategy. Government Strategy, Dublin; 2014.

[5] World Health Organisation. Dementia: A public health priority World Health Organisation and Alzheimer's disease International; 2012.

[6] Ageing and Aged Care. National Framework for Action on Dementia 2015-2019. Australian Government: Department of Health; 2015.

[7] Boye F, Yan E. Abuse of Older Persons With Dementia: A Review of the Literature. Trauma, Violence \& Abuse. 2016.

[8] Downes C, Fealy G, Phelan, et al. Abuse of Older People with Dementia: A review. Dublin: National Centre for the Protection of Older People; 2013.

[9] Tronetti P. Evaluating abuse in the patient with dementia. Clinics in Geriatric Medicine. 2014; 30(4): 825-38. PMid:25439644 https://doi.org/10.1016/j.cger.2014.08.010

[10] Health Service Executive. Safeguarding Vulnerable Persons at Risk of Abuse National Policies and Procedures. Social Care Division. 2014.

[11] United Kingdom Government. Care Act 2014. Legislation.gov.uk: The National Archives; 2014.

[12] Act C. Care Act 2014. London, UK: HMSO; 2014

[13] Donnelly S, O’Brien M. Speaking up about harm: Options for Policy and Practice in the Irish Context. 2018.

[14] Cooper C, Selwood A, Blanchard M, et al. Abuse of people with dementia by family carers: representative cross sectional survey. BMJ. 2009; 338: b155.

[15] Donnelly S, O'Brien M, Walsh J, et al. Adult Safeguarding Legislation and Policy Rapid Realist Literature Review. Dublin: UCD; 2017.

[16] Dong XQ. Elder Abuse: Systematic Review and Implications for Practice. Journal of the American Geriatrics Society. 2015; 63(6): 1214-38. PMid:26096395 https://doi.org/10.1111/jgs.13 454

[17] Health Service Executive. Open Your Eyes. Elder Abuse Services. 2015.

[18] Cooper C, Selwood A, Livingston G. The prevalence of elder abuse and neglect: A systematic review. Age and Ageing. 2008; 37(2): 151-60. PMid:18349012 https://doi .org/10.1093/ageing/a fm194

[19] Cooper C, Selwood A, Blanchard M, et al. Abuse of people with dementia by family carers: representative cross sectional survey. British Medical Journal. 2009; 338.

[20] Cooper C, Blanchard M, Selwood A, et al. Family carers' distress and abusive behaviour: longitudinal study. The British Journal of Psychiatry: the Journal of Mental Science. 2010; 196(6): 480-5. PMid:20513860 https ://doi.org/10.1192/bjp.bp.109.071 811

[21] Van de Weerd C, Paveza G, Walsh M, et al. Physical mistreatment in persons with alzheimers disease. Journal of Aging research. 2013; $1-10$.
[22] Lichtenberg PA. Financial Exploitation, Financial Capacity and Alzheimer's Disease. 2016; 71(4): 312-20.

[23] Wiglesworth A, Mosqueda L, Mulnard R, et al. Screening for Abuse and Neglect of People with Dementia. Journal of the American Geriatrics Society. 2010.

[24] Yan E, Kwok T. Abuse of older Chinese with dementia by family caregivers: an inquiry into the role of caregiver burden. International Journal of Geriatric Psychiatry. 2011; 26(5): 527-35. PMid:20690132 https://doi.org/10.1002/gps. 2561

[25] Andrews J. Abuse of older people: the responsibilites of community nurses. British Journal of Community Nursing. 2017; 22(5): 224 5. PMid:28467241 https://doi.org/10.12968/bjcn.2017.2 2.5 .224

[26] Cooke PJ. Public health nurses experiences of elder abuse: an interpretative phenomenological analysis. University College Cork, Cork; 2016.

[27] Cooke PJ, Day MR, Mulcahy H. Elder abuse: Researching public health nurses'expereinces to inform practice. 17th Annual Research Conference; 23rd November 2017; Catherine McAuley School of Nursing and Midwifery. 2017.

[28] McCaughey C, Laird LA, Reid B. GP's Experience of Managing Elder Abuse: A Qualitative Study. All Ireland Gerontological Nurses Association Journal. 2018; 5(1): 24-31.

[29] Murphy CM, Whelan BJ, Normand C. Formal home-care utilisation by older adults in Ireland: evidence from the Irish Longitudinal Study on Ageing (TILDA). Health \& Social Care in the Community. 2015; 23; 408-18.

[30] Nic Philibin C, Griffiths C, Byrne G, et al. The role of the public health nurse in a changing society. Journal of Advanced Nursing 2010; 66(4): 743-52. PMid:20423362 https ://doi.org/10.111 $1 / j .1365-2648.2009 .05226 . x$

[31] Phelan A. Elder abuse and the community nurse: supporting the patient. British Journal of Community Nursing. 2010; 15(0): 472 8. PMid:20966841 https://doi.org/10.12968/bjcn.2010.1 5.10 .78727

[32] Dening KH, Hibberd P. Exploring the community nurse role in family-centred care for patients with dementia. British Journal of Community Nursing. 2016; 21(4): 198-202. PMid:27282506 https://doi.org/10.12968/bjcn.2016.21.4.198

[33] Yaffe MJ, Wolfson C, Lithwick M. Professions show different enquiry strategies for elder abuse detection: Implications for training and inter-professional Care. 2009; 23(6): 646-54.

[34] DeLiema M, Navarro A, Enguidanos S, et al. Voices from the frontlines: Examining elder abuse from multiple professional perspectives. Health \& Social Work. 2015; 40(2): e15-e24.

[35] Erlingson CL, Carlson SL, Saveman BI. Perceptions of elder abuse: Voices of professionals and volunteers in Sweden-an exploratory study. 2006; 20(2): 151-9.

[36] Wong C, Marr S. Factors influencing health-care professionals in identifying and managing elder abuse: a preliminary report. Geriatrics Today. 2002; 5: 34-7.

[37] McCreadie C, Bennet G, Gilthorpe MS, et al. Elder abuse: do general practitioners know or care? Journal of the Royal Society of Medecine. 2000; 93(2): 67-71. PMid:10740572 https: //doi.org/10.1177/014107680009300205

[38] O'Brien JG, Riain AN, Collins C, et al. Elder abuse and neglect: A survey of Irish general pracitioners. Journal of Elder Abuse and Neglect. 2014; 26(3): 291-9. PMid:24779541 https ://doi .org/ 10.1080/08946566.2013.827955

[39] Jones JS, Walker G, Krohmer JR. To report or not to report: emergency services response to elder abuse. Prehospital and Disaster 
Medicine. 1995; 10(2): 96-100. https://doi.org/10.1017/S1 049023X00041790

[40] Winterstein TB. Nurses' experiences of the encounter with elder neglect. Journal of Nursing Scholarship. 2012; 44(1): 55-62. PMid:22340016 https://doi .org/10.1111/j.1547-5069.20 11.01438.x

[41] O'Donnell D, Treacy MP, Fealy G, et al. The Case Management Approach to Protecting Older People from Abuse and Mistreatment: Lessons from the Irish Experience. The British Journal of Social Work. 2015; 45(5): 1451-68. https://doi.org/10.1093/bjsw /bcu027

[42] Sandmoe A, Kirkevold M, Ballantyne A. Challenges in handling elder abuse in community care. An exploratory study among nurses and care coordinators in Norway and Australia. Journal of Clinical Nursing. 2011; 20(23-24): 3351-63. PMid:21951378 https: //doi.org/10.1111/j.1365-2702.2011.03863.x

[43] Schmeidel AN, Daly JM, Rosenbaum ME, et al. Health care professionals' perspectives on barriers to elder abuse detection and reporting in primary care settings. Journal of Elder Abuse \& Neglect. 2012; 24(1): 17-36. PMid:22206510 https://doi .org/10.1080/0894 6566.2011 .608044

[44] Naughton C, Treacy MP, Drennan J, et al. Abuse and Neglect of Older People in Ireland: Report on the National Study of Elder Abuse and Neglect. National Centre for the Protection of Older People (NCPOP). 2010.

[45] Lo SK, Lai CK, Tsui CM. Student nurses' perception and understanding of elder abuse. International Journal of Older People Nursing. 2010; 5(4): 283-9. PMid:21083807 https://doi.org/10.1111/ j.1748-3743.2009.00196.x

[46] Erlingson CL, Carlson SL, Saveman BI. An international collaborative study comparing Swedish and Japanese nurses reactions to elder abuse. Journal of Advanced Nursing. 2012; 68(1): 56-68. PMid:21627683 https://doi.org/10.1111/j.1365-2648.20 11.05712.x

[47] Friedman B, Santos EJ, Liebel DV, et al. Longitudinal prevalence and correlates of elder mistreatment among older adults receiving home visiting nursing. Journal of Elder Abuse \& Neglect. 2015 27(1): 34-64. PMid:25208218 https://doi .org/10.1080/0894 6566.2014 .946193

[48] Cairns J, Vreugdenhil A. Working at the frontline in cases of elder abuse: It keeps me awake at night. Australian Journal on Ageing. 2014; 33(1): 59-62. PMid:24521488 https://doi.org/10.111 1/ajag. 12017

[49] O'Donnell D, Treacy M, Fealy G, et al. Managing elder abuse in Ireland: Senior case workers' experiences. NCPOP, University College Dublin. 2012.

[50] O'Donnell D, Treacy MP, Fealy G, et al. The case management approach to protecting older people from abuse and mistreatment: Lessons from the Irish experience. The British Journal of Social Work. 2014; 45(5): 1451-68. https://doi.org/10.1093/bjsw /bcu027

[51] Marnin T, Doron I. Elder abuse and neglect in Israel: To report or to inform? Community nurses' perspective on a policy dilemma In: Li Y, editor. Global Aging Issues and Policies: Understanding the Importance of Comprehending and Studying the Aging Process. Illinois: Charles C. Thomas Publisher Ltd; 2013; 74-90.

[52] Smith J, Flowers P, Larkin P. Interpretative Phenomenological Analysis: Theory, Method and Research. London: Sage; 2009.

[53] Larkin M, Thompson A. Interpretative Phenomenological Analysis. 2012.

[54] Smith J, Osborn M. Interpretative Phenomenological Analysis. In: Breakwell GM, editor. Doing Social Psychology Research. London: British Psychological Society; 2004; 229-54.
[55] Ashton S. Researcher or nurse? Difficulties of undertaking semistructured interviews on sensitive topics. Nurse Researcher. 2014; 22(1): 27-31. PMid:25251817 https://doi .org/10.7748/nr.2 2.1.27.e1255

[56] Central Statistics Office. Census 2016 Profile 3 - An Age Profile of Ireland,. CSO Office, Cork; 2017.

[57] Health Service Executive. 2016 Safeguarding Report. National Safeguarding Office, HSE; 2018.

[58] Cahill S, O'Shea E, Pierce M. Creating excellence in dementia care: A research review for Ireland's national dementia strategy. The School of Social Work and Social Policy: Trinity College, Dublin and The Irish Centre for Social Gerontology, NUIG; 2012.

[59] World Alzheimer Report. The Global Impact of Dementia An analysis of prevalence, incidence, cost and trends. Alzheimer's Disease International (ADI), London; 2015.

[60] Dong X, Simon M, Rajan K, et al. Association of Cognitive Function and Risk for Elder Abuse in a Community-Dwelling Population. Dementia and Geriatric Cognitive Disorders. 2011; 32(3): 209-15. PMid:22095098 https://doi.org/10.1159/000334047

[61] Dong X, Chen R, Simon MA. Elder abuse and dementia: a review of the research and health policy. Health affairs (Project Hope). 2014; 33(4): 642-9. PMid:24711326 https://doi.org/10.1377/hlth aff. 2013.1261

[62] Fang B, Yan E. Abuse of Older Persons with Dementia: A Review of the Literature. Trauma, Violence \& Abuse. 2016; 19(2): 127-47.

[63] Dong XQ. Elder Abuse: Systematic Review and Implications for Practice. Journal of American Geriatrics Society. 2015; 63(6): 121438. PMid:26096395 https://doi .org/10.1111/jgs. 13454

[64] California Probate Code. California Probate Code. Desktop Edition. San Fransisco: Thomson Reuters; 2015.

[65] Ziminski Pickering CE, Phillips LR. Development of a causal model for elder mistreatment. Public Health Nursing. 2014; 31(4): 363-72. PMid:24547693 https://doi.org/10.1111/phn.12108

[66] Benner P. From novice to expert: Excellence and power in clinical nursing practice. Menlo Park, CA: Addison-Wesley Publishing company; 1984.

[67] Yan E. Abuse of older persons with dementia by family caregivers: results of a 6-month prospective study in Hong Kong. International Journal of Geriatric Psychiatry. 2014; 29(10): 1010-27. PMid:24615822

[68] Orfila F, Coma-Sole M, Cabanas M, et al. Family caregiver mistreatment of the elderly: prevalence of risk and associated factors. 2018; 18(1): 167.

[69] Baker PR, Francis DP, Hairi NNM, et al. Interventions for preventing elder abuse: applying findings of a new Cochrane review. Age and Ageing. 2017; 46(3): 346-8.

[70] O'Donnell D, Treacy M, Fealy G, et al. Managing elder abuse in Ireland: Senior case workers' experiences. University College Dublin: NCPOP; 2012.

[71] McCausland B, Knight L, Page L, et al. A systematic review of the prevalence and odds of domestic abuse victimization among people with dementia. International review of psychiatry (Abingdon, England). 2016; 28(5): 475-84. PMid:27564566 https ://doi .org/10 $.1080 / 09540261.2016 .1215296$

[72] Touza Garm C. Influence of health personnel's attitudes and knowledge in the detection and reporting of elder abuse: An exploratory systematic review. Psychosocial Intervention. 2017; 26(2): 73-91. https://doi.org/10.1016/j.psi.2016.11.001

[73] Donnelly S, O'Brien M. Speaking up about harm: Options for Policy and Practice in the Irish Context. Cork: University College Cork; 2018. 